\title{
Erratum to: A case of successful preoperative chemotherapy with cisplatin and irinotecan followed by curative-intent surgery for locally advanced thymic carcinoma
}

\author{
Shigeki Suzuki · Hirotoshi Horio · Tai Hato • \\ Masahiko Harada · Yusuke Okuma • \\ Tsunekazu Hishima
}

Published online: 19 September 2012

(C) The Japanese Association for Thoracic Surgery 2012

\section{Erratum to: Gen Thorac Cardiovasc Surg}

DOI 10.1007/s11748-012-0123-2

The last two sentences in the article, immediately preceding the reference section, were erroneously inserted and should be deleted.

The online version of the original article can be found under doi:10.1007/s11748-012-0123-2.

S. Suzuki $(\varangle) \cdot$ H. Horio $\cdot$ T. Hato $\cdot$ M. Harada

Department of Thoracic Surgery, Tokyo Metropolitan Cancer and Infectious Diseases Center Komagome Hospital,

3-18-22 Honkomagome, Bunkyo, Tokyo 113-8677, Japan

e-mail: shgeki1209@yahoo.co.jp

Y. Okuma

Department of Respiratory Medicine and Thoracic Oncology,

Tokyo Metropolitan Cancer and Infectious Diseases Center

Komagome Hospital, Tokyo, Japan

T. Hishima

Department of Pathology, Tokyo Metropolitan Cancer and

Infectious Diseases Center Komagome Hospital, Tokyo, Japan 